\title{
Temporal haemodynamic changes after bisoprolol treatment in patients with uncontrolled hypertension
}

\author{
Weiwei Zeng ${ }^{1}$, Brian Tomlinson ${ }^{2,3} \wedge$ \\ ${ }^{1}$ Department of Pharmacy, Shenzhen Baoan Women's and Children's Hospital, Jinan University, Shenzhen, China; ${ }^{2}$ Faculty of Medicine, Macau \\ University of Science and Technology, Taipa, Macau, China; ${ }^{3}$ Department of Medicine \& Therapeutics, The Chinese University of Hong Kong, \\ Prince of Wales Hospital, Shatin, Hong Kong, China \\ Contributions: (I) Conception and design: B Tomlinson; (II) Administrative support: B Tomlinson; (III) Provision of study materials or patients: B \\ Tomlinson; (IV) Collection and assembly of data: W Zeng; (V) Data analysis and interpretation: W Zeng; (VI) Manuscript writing: Both authors; (VII) \\ Final approval of manuscript: Both authors. \\ Correspondence to: Prof. Brian Tomlinson. Faculty of Medicine, Macau University of Science and Technology, Taipa, Macau, China. \\ Email: btomlinson@must.edu.mo.
}

Background: Anti-hypertensive drugs are widely used to control blood pressure, yet their effects on haemodynamics, especially in Chinese populations, and the potential for non-invasive methods to monitor these changes, are poorly understood. This study aimed to determine the early and late effects of bisoprolol treatment on blood pressure, cardiac output (CO), stroke volume (SV), heart rate (HR), systematic vascular resistance (SVR), and inotropy measured in Chinese patients with hypertension.

Methods: Twelve Chinese subjects (median age: 55 years, interquartile range: $52-58$ years; $33 \%$ male) with uncontrolled hypertension were recruited at the Prince of Wales Hospital in Hong Kong and haemodynamic measurements were assessed using a non-invasive Ultrasonic Cardiac Output Monitor (USCOM). Seven hourly measurements were taken before and after bisoprolol $2.5 \mathrm{mg}$ on day 1 (T0 to T6), and in nine patients this was repeated six weeks later (TF0 to TF6). Any BP change of $5 \mathrm{mmHg}$ was considered clinically significant and $\mathrm{P}<0.05$ was considered statistically significant.

Results: On day $1(\mathrm{~N}=12)$, there was a significant drop in median CO [4.9 (4.7-5.6) vs. $3.8(3.3-4.7) \mathrm{L} / \mathrm{m}^{2}$, $\mathrm{P}<0.0001]$ associated with a compensatory increase in SVR $[1,698.1(1,584.6-1,894.3)$ vs. 2,222.6 (1,777.42,712.5) d.s. $\left.\mathrm{cm}^{-5}, \mathrm{P}<0.0001\right]$ at T2. The median $\mathrm{dBP}\{92$ [87-95] vs. 86 [79-89] mmHg, $\mathrm{P}=0.0002\}$ and MAP $\{110$ [104-114] vs. 104 [101-109] mmHg, $\mathrm{P}=0.038\}$ reduced significantly 6 hours after bisoprolol treatment. Except for HR, all other measured haemodynamics returned to baseline at T6. On week $6(\mathrm{~N}=9)$, SVR was generally reduced, but major parallel swings in CO and SVR were still evident. All patients showed a trend to lower blood pressure, SVR, and inotropy $(\mathrm{P}<0.05)$, but HR, SV, and CO returned to baseline values after 6 weeks treatment $(\mathrm{P}>0.05)$.

Conclusions: The acute haemodynamic changes between 6 hours of the first dose and the dose after 6 weeks of bisoprolol treatment are similar. Long-term therapy can effectively reduce blood pressure by reducing SVR.

Keywords: Bisoprolol; haemodynamics; hypertension; ultrasonic cardiac output monitor

Submitted Mar 24, 2021. Accepted for publication May 18, 2021.

doi: 10.21037/atm-21-1796

View this article at: http://dx.doi.org/10.21037/atm-21-1796

$\wedge$ ORCID: 0000-0001-6717-5444. 


\section{Introduction}

Hypertension is highly prevalent in all developed countries, and a major risk factor for cardiovascular diseases (1) with high morbidity and mortality (2). Around $70 \%$ of patients diagnosed with congestive heart failure, a first myocardial infarction, or stroke, have hypertension (3). Hypertension affects $46 \%$ of adults in the USA (4), $44.7 \%$ of adults in China (5), and among these patients, over $50 \%$ may not be aware of their high blood pressure, with only $7.2 \%$ of patients achieving control (5). Even for normotensive people at age 55 years, there is a $90 \%$ lifetime risk of developing high blood pressure (6). According to the World Health Organization (WHO), one in three adults worldwide have raised blood pressure (BP), causing around half of all deaths from stroke and heart disease (7).

Mean arterial pressure (MAP) is influenced by cardiac output $(\mathrm{CO})$ and systemic vascular resistance (SVR) according to the equation: $\mathrm{MAP}=\mathrm{CO} \times \mathrm{SVR}$. Any elevation in either or both of CO and SVR will increase MAP trending towards hypertension, unless there is an equally balanced, compensatory change in the other (8). Although changes in CO and SVR are a final common pathway to MAP, they are both influenced by immediate, acute, and chronic changes in four systems-the autonomic system, the renin-angiotensin system, the renal system, and the cardiovascular system (9). While measuring CO and SVR does not enhance our understanding of how interventions directly influence these four systems, it will provide insight into the temporal and dose relationships of the final common pathway, which finally determines BP.

$\beta$-blockers represent an important antihypertensive drug class which were initially introduced as first line therapy for improving blood pressure control, heart failure, angina, and post-myocardial infarction (10). $\beta$-blockers can reduce blood pressure either by reducing $\mathrm{CO}$ or systemic vascular resistance (11) and a reduction of blood pressure by $5 \mathrm{mmHg}$ decreases the 10-year risk of stroke by $34 \%$ and ischemic heart by $21 \%$, and reduces the possibility of dementia, heart failure, and mortality from cardiovascular disease (12). The latest European Society of Hypertension and European Society of Cardiology guidelines still suggest that $\beta$-blockers should still be considered first-line drugs for the treatment of hypertension (13).

Bisoprolol, (+/-)1-(4-((2-isopropoxyethoxy)-methyl)phenoxy)-3-isopropyl-amino-2-propanol hemifumarate, is a $\beta_{1}$ selective adrenergic receptor antagonist and an effective and safe antihypertensive agent (14). In patients with mild to moderate essential hypertension, a daily dose of $2.5 \mathrm{mg}$ bisoprolol effectively reduces blood pressure without unfavorable effects $(15,16)$. However, although bisoprolol effectively reduces blood pressure, most related published studies have not investigated the detailed temporal relationships of haemodynamic changes, such as $\mathrm{CO}$ and SVR, associated with its use. Individuals treated with the same antihypertensive drug may respond differently according to the therapeutic mechanism, which in turn may be affected by age $(17,18)$, gender $(19,20)$ and the duration of therapy.

Haemodynamics can be evaluated safely, accurately, and reliably through non-invasive and reproducible methods (21-24) and previous studies have evaluated the potential for transthoracic impedance methods to evaluate CO and SVR. USCOM is a potentially more accurate method of measuring CO than other non-invasive devices as it measures blood flow directly across aortic or pulmonary valves, and provides a more direct assessment of true CO (25).

Using non-invasive transcutaneous Doppler ultrasound, this study investigated early and late haemodynamic changes associated with bisoprolol treatment including changes in stroke volume (SV), heart rate (HR), CO, SVR, and inotropy in Chinese patients. We present the following article in accordance with the STROBE reporting checklist (available at http://dx.doi.org/10.21037/atm-21-1796).

\section{Methods}

\section{Ethics}

The study was approved by the Joint Clinical Research Ethics Committee of the Chinese University of Hong Kong and New Territories East Cluster (CUHK-NTEC) (CREC Ref. No.: 2011.616-T), and informed written consent was obtained from all patients. The study was conducted in accordance with the Declaration of Helsinki (as revised in 2013) and Good Clinical Practice Guidelines (26,27).

\section{Study design}

This was an uncontrolled, prospective observational study to investigate haemodynamic changes after treatment with bisoprolol.

\section{Subject recruitment}

Patients with a de novo diagnosis of essential hypertension or a known history of essential hypertension who attended outpatient clinics in the Prince of Wales Hospital (Shatin, Hong Kong) during the period of June 2012 to July 2014 


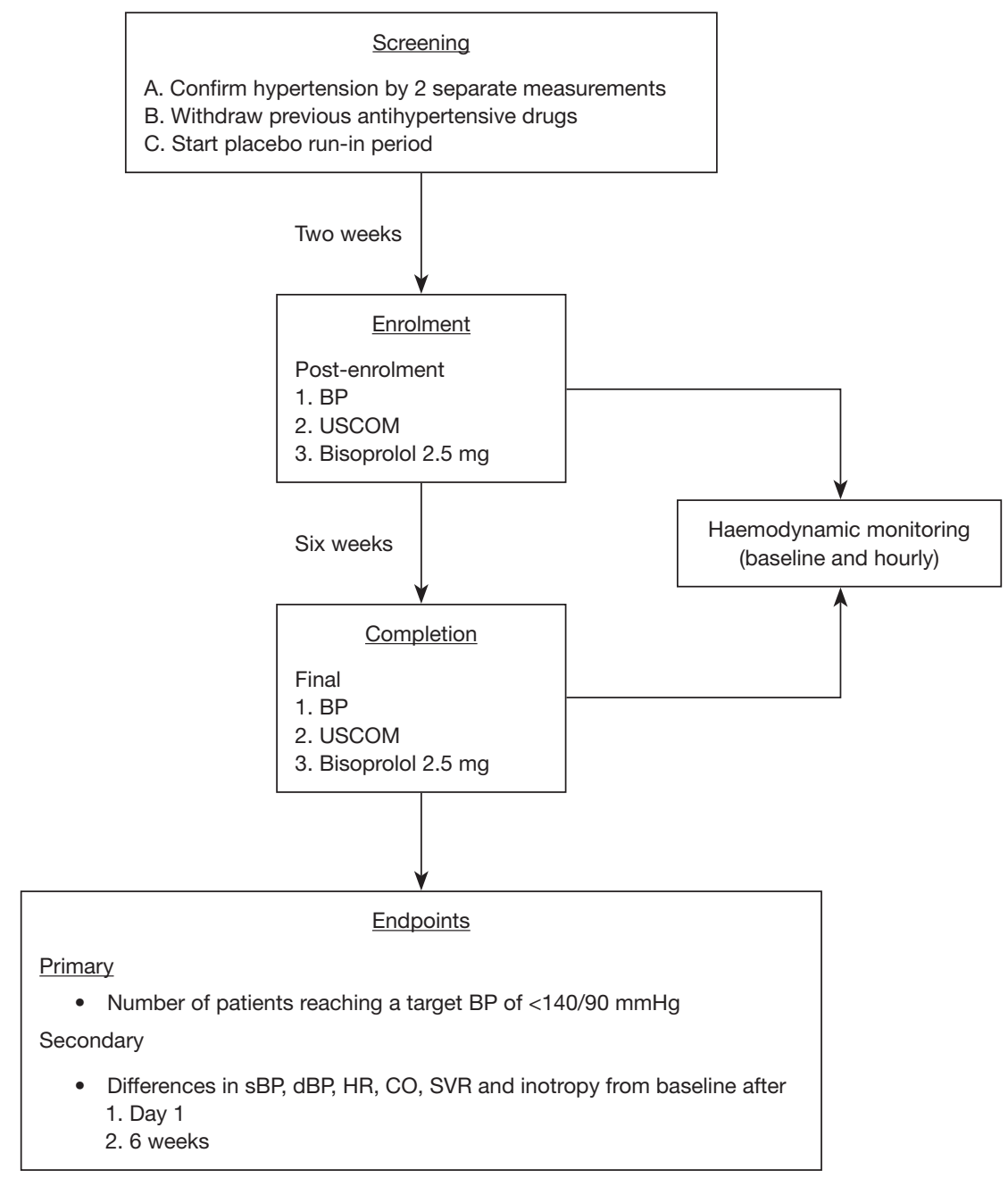

Figure 1 Study flow chart. sBP, systolic blood pressure; dBP, diastolic blood pressure; HR, heart rate; CO, cardiac output; SVR, systematic vascular resistance.

were recruited. Inclusion criteria were: age 18-79 years with sitting clinic systolic blood pressure of $140-169 \mathrm{mmHg}$ (130-169 $\mathrm{mmHg}$ for diabetes) and/or a sitting clinic diastolic blood pressure of $90-109 \mathrm{mmHg}(80-109 \mathrm{mmHg}$ for diabetes); patients on other antihypertensive treatments who were experiencing side effects, or whose blood pressure could not be well controlled. Exclusion criteria were: secondary hypertension; pregnant or lactating women and women with childbearing potential not using adequate methods of contraception or agreeing to maintain sexual abstinence throughout the study; unstable angina, myocardial infarction, stroke, or coronary heart disease in the previous 3 months; heart failure with New York Heart Association (NYHA) class III-IV; haemodynamically relevant aortic or mitral valve disease; obstructive hypertensive cardiomyopathy; symptomatic bradycardia, second or third degree AV block, sick sinus syndrome, sinoatrial block; primary hyperaldosteronism; renal artery stenosis; impairment of hepatic or renal function as defined by liver function values of alanine aminotransferase $\geq 1$. 5 -fold the upper normal limit or serum creatinine $>150 \mu \mathrm{mol} / \mathrm{L}$; history of intolerance to beta-blockers; known contraindication to beta-blockers such as bradycardia, asthma, or severe peripheral vascular disease.

\section{Intervention}

Figure 1 shows the study flow chart. After recruitment, subjects were withdrawn from previous antihypertensive therapy and took placebo once daily for at least 2 weeks. 
The placebo run-in period is a standard feature of clinical trials of antihypertensive drugs to establish compliance with medication and to provide a more reliable baseline of blood pressure. Subjects who did not take placebo more than $20 \%$ of the days during the placebo run-in period were excluded from the study. After the run-in period, bisoprolol $2.5 \mathrm{mg}$ was taken once daily for 6 weeks. A stable dose of a calcium channel blocker, either amlodipine or nifedipine retard, was allowed for patients experiencing side effects or obtaining uncontrolled blood pressure on other antihypertensive treatments. Other medication which was considered necessary for the patient's safety was also maintained.

\section{Measurements}

An Ultrasonic Cardiac Output Monitor $\left(\mathrm{USCOM}^{\circledR}\right.$; USCOM Pty Ltd, NSW, Australia) and an electronic blood pressure monitor (Omron HEM-CR24; Healthcare, Inc., US) were used to assess haemodynamics and the blood pressure of patients, respectively. Measurements started at 10 to $11 \mathrm{am}$ in all cases. On the first day of treatment, seven hourly measurements were taken before and after bisoprolol $2.5 \mathrm{mg}$ (T0 to T6), then 6 weeks later, on day 42 ( \pm 5 days), patients were reassessed with seven further hourly measurements (TF0 to TF6). While patients were not allowed to take meals ten hours before the baseline measurement, a light lunch (sandwiches) was provided for all subjects between $\mathrm{T} 3$ and $\mathrm{T} 4$, and between TF3 and TF4.

USCOM scans were performed on patients in the supine position to measure direct and derived haemodynamic responses to bisoprolol. A transducer was placed either on the suprasternal notch or on the chest in the left parasternal position to measure transaortic or transpulmonary blood flow, respectively. At least three consecutive cycles were obtained for each scan and each patient was scanned a minimum of three times each hour. USCOM was performed by an experienced and trained researcher.

The Omron HEM-CR24 blood pressure monitor was used to measure the blood pressure of patients in the supine position just before each haemodynamic assessment using USCOM. These values were then entered into the USCOM device. Body height was measured at baseline and body weight was measured at each visit.

\section{Definitions}

Mean arterial pressure (MAP) is defined by the amount of pressure exerted against the arterial wall during contraction. It is calculated by the equation: $\mathrm{MAP}=\frac{1}{3} \mathrm{sBP}+\frac{2}{3} \mathrm{dBP}$, the unit is $\mathrm{mmHg}$, and the target $\mathrm{MAP}$ is $<105 \mathrm{mmHg}$.

$\mathrm{SV}$ is the volume (in $\mathrm{mL}$ ) of blood ejected from the heart during one systolic stroke and the normal range is 64-100 mL (27).

$\mathrm{CO}$ is the volume of blood pumped by the heart in one minute. It is calculated by the equation: $\mathrm{CO}=$ heart rate $(\mathrm{HR}) \times \mathrm{SV}$, the unit is $\mathrm{L} / \mathrm{min}$ and the normal range of $\mathrm{CO}$ is $5-7 \mathrm{~L} / \mathrm{min}(27)$.

Systemic vascular resistance (SVR) is the resistance (in $\mathrm{d} \cdot \mathrm{s} \cdot \mathrm{cm}^{-5}$ ) offered by the peripheral circulation in the blood circulatory system. It is calculated by the equation: SVR = $\mathrm{MAP} / \mathrm{CO}$ and the normal range is $1,000-1,600 \mathrm{~d} \cdot \mathrm{s} \cdot \mathrm{cm}^{-5}(27)$.

Inotropy indicates myocardial contractility, which describes the relative ability of the heart to eject a $\mathrm{SV}$ at a given prevailing afterload (arterial pressure) and preload (end-diastolic volume) (28). The unit of inotropy is $\mathrm{W} / \mathrm{m}^{2}$.

\section{Primary outcome}

The primary outcome was the number of patients reaching a target BP of $<140 / 90 \mathrm{mmHg}$ after 6 weeks of treatment of bisoprolol. The secondary outcomes were the differences in sBP, dBP, HR, CO, SVR, and inotropy from baseline after 1 day and 6 weeks treatment of bisoprolol. As USCOM has an inter-operator coefficient of variation of $<11 \%$ $(29,30)$, and changes of $>11 \%$ assessed by USCOM may be regarded as haemodynamically significant. By comparison, the Omron blood pressure machine has an inter-operator coefficient of variation of $16 \%$ (31). Despite this range of variation, any change in $\mathrm{BP}$ of $\geq 5 \mathrm{mmHg}$ was considered clinically significant (12).

\section{Statistical analysis}

Data were analyzed using the Statistical Package for the Social Sciences (SPSS) statistical software for Windows, Version 20.0 (SPSS Inc., IL, USA). Haemodynamic changes before and after bisoprolol treatment were analyzed using the Wilcoxon signed-rank test and Friedman test as appropriate. Figures were plotted using Microsoft Excel 2010 and presented as median (interquartile range). Any BP change of $5 \mathrm{mmHg}$ was considered clinically significant and $\mathrm{P}<0.05$ was considered statistically significant. 
Table 1 Baseline characteristics of 12 patients with uncontrolled hypertension

\begin{tabular}{lc}
\hline Variable & Value \\
\hline Age (years) & $55[52-58]$ \\
Male gender, $\mathrm{n}(\%)$ & $4(33.0)$ \\
Height, cm & $160.5(154.8-164.9)$ \\
Weight, kg & $59.0(49.0-70.3)$ \\
BSA, ${ }^{2}$ & $1.6(1.6-1.8)$ \\
BMl, kg/m ${ }^{2}$ & $22.8(22.5-25.8)$ \\
Baseline sBP, mmHg & $150[154-155]$ \\
Baseline dBP, mmHg & $92[87-95]$ \\
Baseline MAP, mmHg & $110[104-114]$ \\
Medical history, $\mathrm{n}(\%)$ & \\
Diabetes mellitus & $3(25.0)$ \\
High cholesterol & $4(33.3)$ \\
Other medication, $\mathrm{n}(\%)$ & $3(16.7)$ \\
Amlodipine & $3(25.0)$ \\
Metformin & \\
Statin & \\
\hline All values are expressed & \\
\hline
\end{tabular}

All values are expressed as medians (interquartile range) unless stated otherwise. sBP, systolic blood pressure; dBP, diastolic blood pressure; MAP, mean arterial pressure.

\section{Results}

\section{Subject characteristics}

Twelve Chinese subjects [median age (interquartile range): 54 (52-58) years; 4/12 (33\%) male; BMI: $\left.22.8(22.5-25.8) \mathrm{kg} / \mathrm{m}^{2}\right]$, with uncontrolled hypertension were recruited and assessed using USCOM. Nine subjects were re-assessed after 6 weeks of treatment with bisoprolol $2.5 \mathrm{mg}$ on day $42( \pm 5$ days $)$ and Table 1 shows the baseline characteristics.

\section{Haemodynamics changes}

Figure 2, Tables 2 and 3 show the temporal haemodynamic changes after the first day and $42^{\text {nd }}$ day after bisoprolol treatment. On day 1, bisoprolol was associated with a sustained and significant reduction in median HR, SV, $\mathrm{CO}$, and $\mathrm{dBP}$. There was no significant reduction in $\mathrm{sBP}$ when compared with baseline and the drop in $\mathrm{CO}$ was associated with a compensatory increase in calculated SVR. There were $>11 \%$ changes in all haemodynamic parameters including a $23 \%$ reduction in $\mathrm{CO}$ and $25 \%$ elevation in SVR at T2. Except for HR, all other measured haemodynamics returned to baseline values by $\mathrm{T} 6$.

On Day 42, there were similar changes in pattern across all parameters except that sBP was the lowest at TF6. The reduction in $\mathrm{HR}(11 \%)$ and $\mathrm{CO}(15 \%)$, and rise in SVR $(25 \%)$ from TF0 to TF2, were still significant $(\mathrm{P}<0.05)$ and unlike Day 1 , there was no change in calculated inotropy at day 42 .

Table 4 shows the haemodynamic differences before and after 6 weeks of treatment with bisoprolol. From T0 to TF0 (n=9), the median reduction of sBP and $\mathrm{dBP}$ were $15(10.0 \%)$ and $14(14.2 \%) \mathrm{mmHg}$, respectively. Seven patients successfully reduced $\mathrm{sBP}$ by $>5 \mathrm{mmHg}$ and all patients reduced $\mathrm{dBP}$ by $>5 \mathrm{mmHg}$. $\mathrm{HR}, \mathrm{SV}$, and $\mathrm{CO}$ returned to baseline value after 6 weeks treatment $(\mathrm{P}>0.05)$ and all nine patients showed a trend to lower blood pressure, SVR, and inotropy $(\mathrm{P}<0.05)$. Eight patients successfully reduced their blood pressure to the normal range by week 6 and only one patient still had a borderline $\mathrm{BP}$ with $\mathrm{BP}=145 / 91 \mathrm{mmHg}$ at $\mathrm{TF} 0$.

\section{Discussion}

This study is important for two broad reasons. Firstly, it provides confirmatory evidence of the well-established effects of bisoprolol on blood pressure and haemodynamics. Secondly, it provides novel findings, which as far as we are aware, have not been previously reported.

We have shown that on day 1 although there was little change in sBP over 6 hours after low-dose $(2.5 \mathrm{mg})$ bisoprolol treatment, within two hours both median MAP and $\mathrm{dBP}$ were reduced by $>5 \mathrm{mmHg}$, and this was associated with a $>10 \%$ reduction in median HR and CO. These reductions were also associated with a similar but opposite compensatory change in calculated SVR. While many studies have demonstrated that bisoprolol can effectively reduce blood pressure $(32,33)$, these studies have not described the detailed temporal changes in haemodynamics shortly after taking low-dose bisoprolol.

Bisoprolol is highly selective towards $\beta 1$ adrenergic receptors, thereby blocking access and the effects of catecholamines, inactivating the sympathetic response, and consequently causing a drop in epinephrine activity and a reduction in HR and CO (34). Bisoprolol also reduces the production of the vasoconstrictive endothelin-1 and thromboxane, resulting in a drop in epinephrine and plasma renin activity (35). It is noteworthy that bisoprolol 

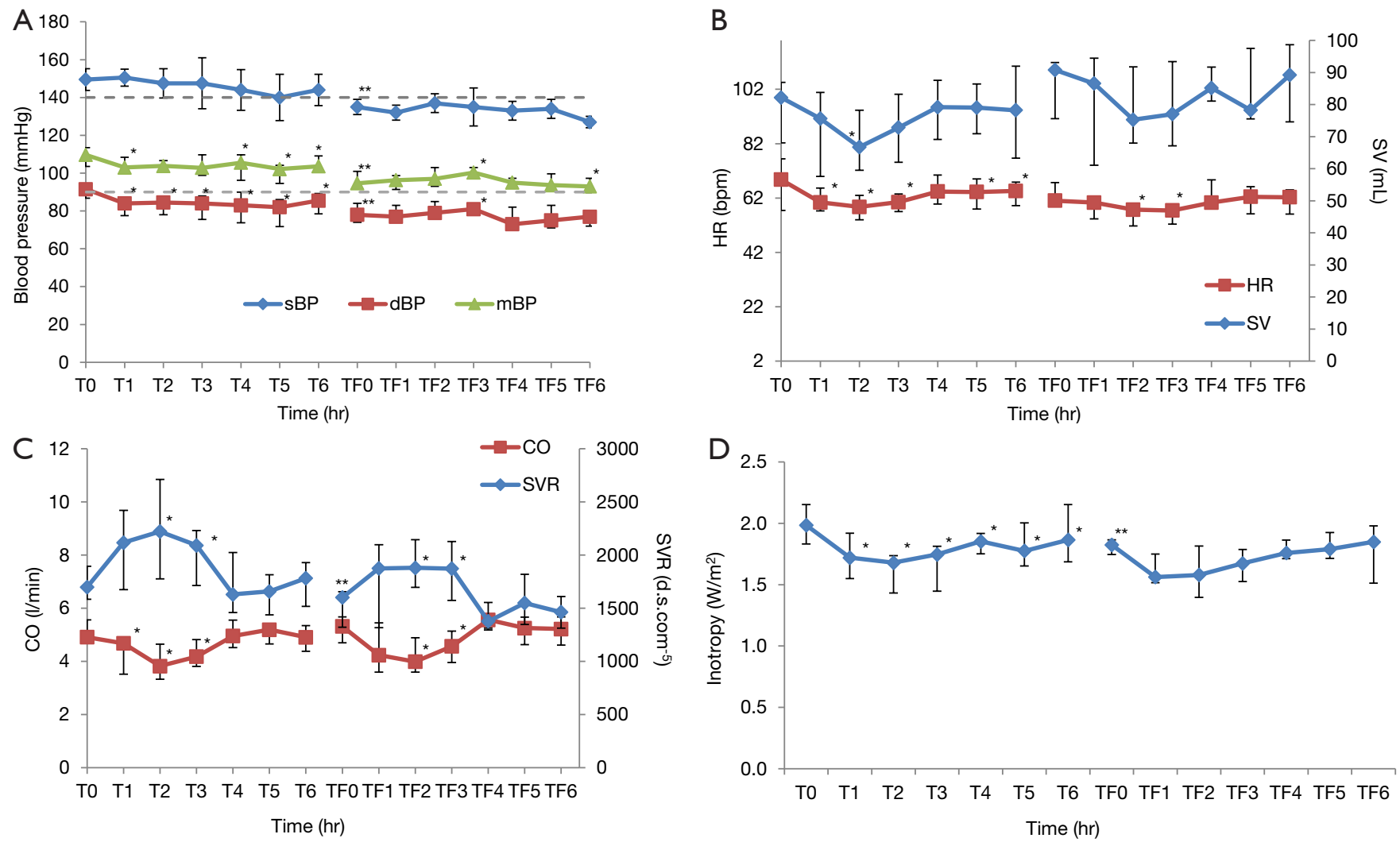

Figure 2 Haemodynamic changes after 6 weeks of bisoprolol treatment. (A) Changes of blood pressure after 6 weeks of treatment with bisoprolol. Data is presented as median (IQR). The dashed line indicates normal range of blood pressure (sBP $<140$ and $\mathrm{dBP}<90 \mathrm{mmHg})$. denotes a statistically significant difference $(\mathrm{P}<0.05)$ between T0 and T1-T6 (or between TF0 and TF1-TF6) and ** denotes a statistically significant difference $(\mathrm{P}<0.05)$ between T0 and TF0 using the Wilcoxon signed-rank test. (B) Changes of heart rate and stroke volume after 6 weeks of treatment with bisoprolol. Data is presented as median (IQR). * denotes a statistically significant difference $(\mathrm{P}<0.05)$ between $\mathrm{T} 0$ and T1-T6 (or between TF0 and TF1-TF6). (C) Changes of cardiac output and systemic vascular resistance after 6 weeks of treatment with bisoprolol. Data is presented as median (IQR). * denotes a statistically significant difference $(\mathrm{P}<0.05)$ between T0 and T1-T6 (or between TF0 and TF1-TF6) and ** denotes a statistically significant difference $(\mathrm{P}<0.05)$ between $\mathrm{T} 0$ and TF0 using the Wilcoxon signed-rank test. (D) Changes of inotropy after 6 weeks of treatment with bisoprolol. Data is presented as median (IQR). * denotes a statistically significant difference $(\mathrm{P}<0.05)$ between T0 and T1-T6 (or between TF0 and TF1-TF6) and ** denotes a statistically significant difference $(\mathrm{P}<0.05)$ between T0 and TF0 using the Wilcoxon signed-rank test.

has little effect on $\beta_{2}$ receptors (36), which normally mediate arterial vasodilation and which, when stimulated, cause a decline in SVR.

The first important aspect in this case series is that these trending features can easily be assessed in hypertensive patients using USCOM, an easy to use, quick, reliable, inexpensive, and non-invasive method for assessing haemodynamics (37). It has acceptable inter-operator agreement, and haemodynamic variables can be generated within a few minutes.

Few studies have investigated the longer term response, resetting of thresholds, and compensatory mechanisms after bisoprolol treatment. We followed up our patients at 6 weeks after continuous ingestion of daily $2.5 \mathrm{mg}$ bisoprolol therapy and found clinical and statistically significant decreases in sBP, MAP, and dBP were evident compared with day 1, and short-term hourly changes in sBP, MAP, $\mathrm{dBP}, \mathrm{HR}$, and $\mathrm{CO}$ were also similar to day 1. Therefore the effects of low-dose bisoprolol and the compensatory haemodynamic mechanisms were as responsive at week 6 as on day 1. Further, by 6 weeks, blood pressure was successfully and significantly reduced to the normal range 


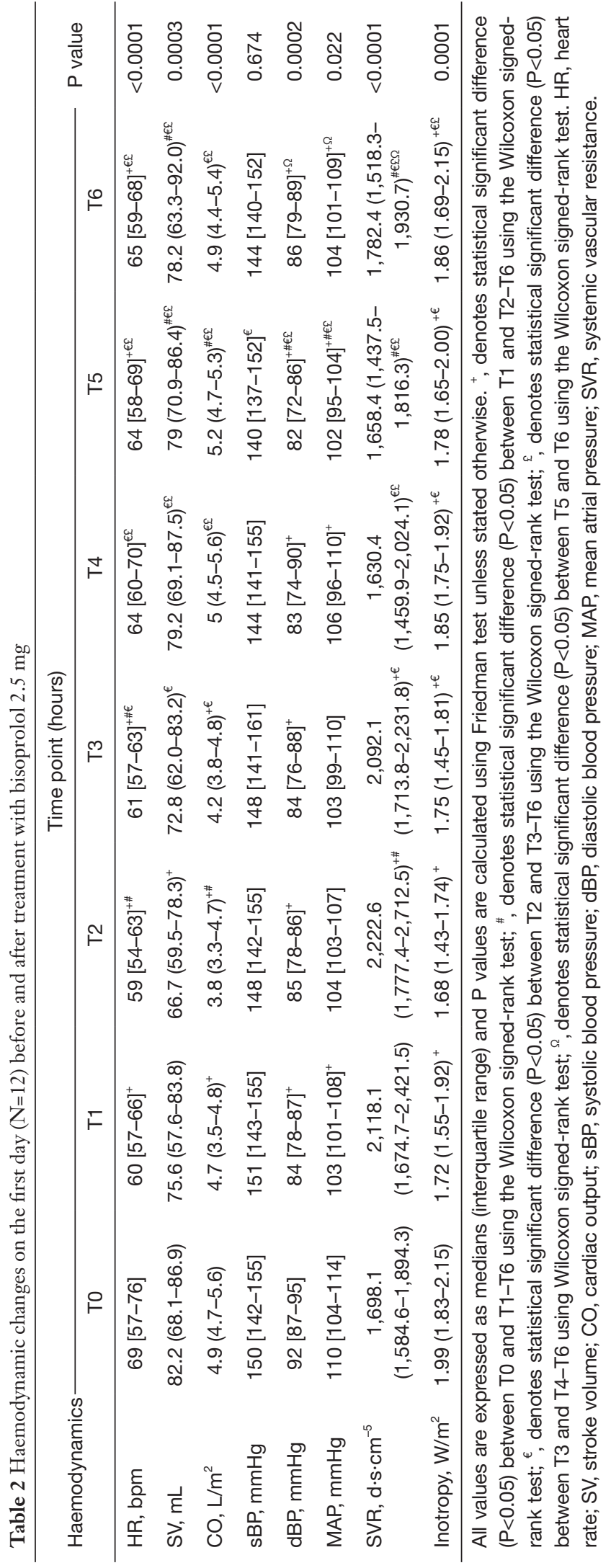

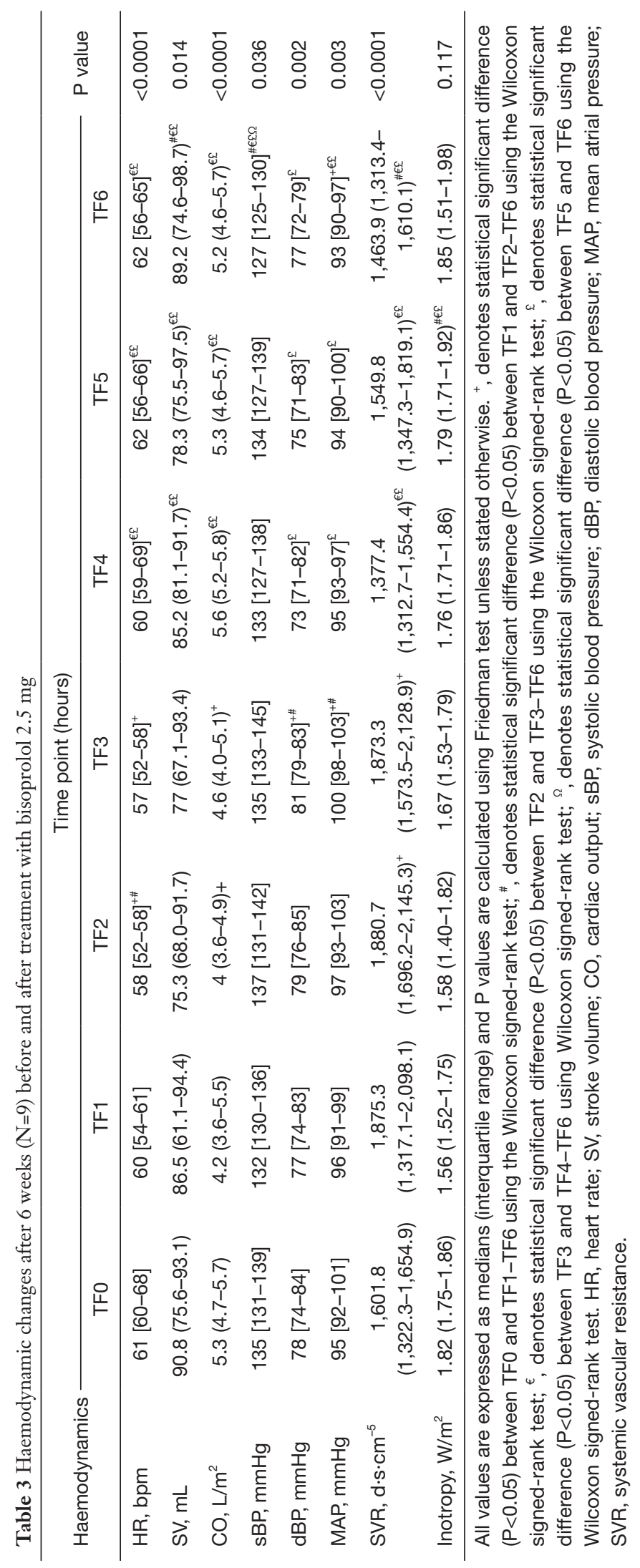


Table 4 Haemodynamic differences before and after 6 weeks of treatment with bisoprolol $2.5 \mathrm{mg}(\mathrm{n}=9)$

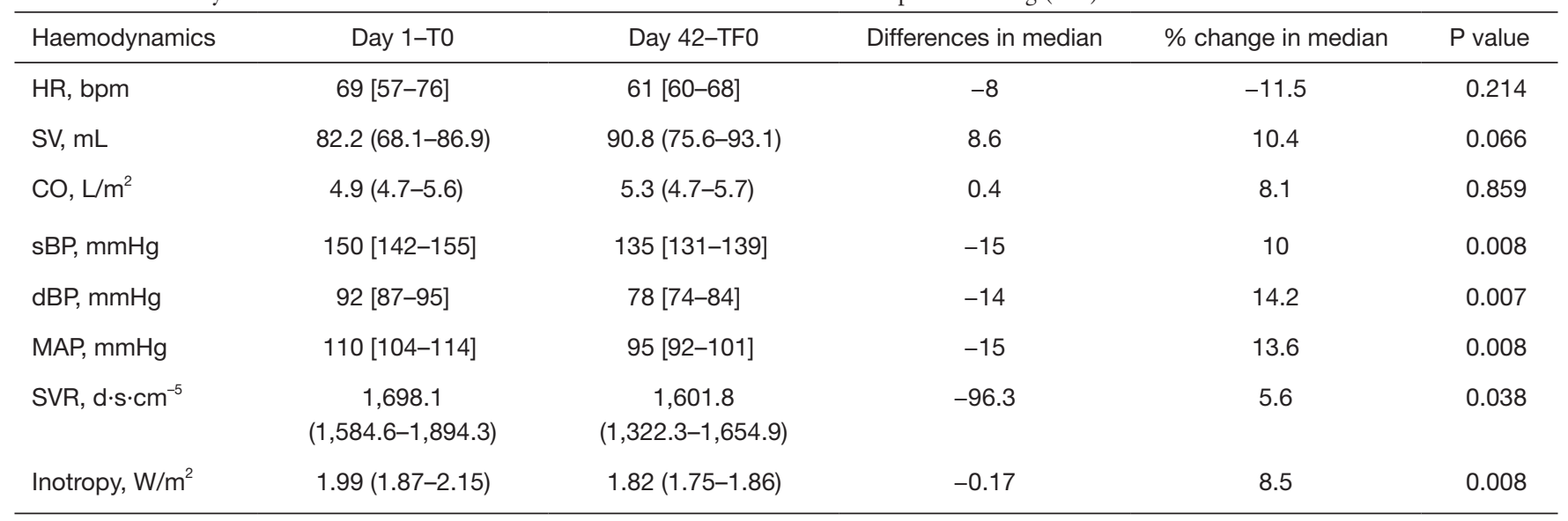

All values are expressed as medians (interquartile range) and $\mathrm{P}$ values are calculated using Wilcoxon signed-rank test. HR, heart rate; SV, stroke volume; CO, cardiac output; sBP, systolic blood pressure; dBP, diastolic blood pressure; MAP, mean atrial pressure; SVR, systemic vascular resistance.

in most patients.

Similar to our study, other $\beta$ blockers such as propranolol, acebutolol, and atenolol (38) all cause significant but transitory reductions in $\mathrm{HR}, \mathrm{SV}$, and $\mathrm{CO}$ within 2 hours of treatment, followed by a return to baseline values after 6 hours after treatment. In our study, bisoprolol was associated with a transient increase in calculated SVR both on day 1 and after 6 weeks. This is different from other $\beta$ blockers, which are associated with a $10 \%$ decrease in SVR at 4 hours after treatment and the differences in haemodynamic profile may be due to the different levels of sympathetic drive and intrinsic sympathomimetic activity among $\beta$ blockers (38). Another possible reason for this is because bisoprolol, unlike atenolol, may effectively reduce central aortic pressure (39), which may be more clinically relevant.

Although other $\beta$ blockers cause a reduction in SV, we are not aware that this has been shown for bisoprolol. We have shown that the reduction in CO after bisoprolol is associated not only with a reduction in HR but also a reduction in $\mathrm{SV}$.

The overall effect of $\beta$ blockers on cardiac function is important. There are many different ways of assessing cardiac function such as HR, SV, CO, and ejection fraction, but one unifying parameter is cardiac inotropy. Inotropy is an important concept but hard to measure and to monitor in clinical practice. Recently, it has been shown that calculated inotropy can be measured by USCOM, and that there are potentially important differences between normal and
NYHA IV heart failure patients (30). It is unclear whether calculated inotropy is valid, and studies confirming whether optimizing inotropy influences clinical outcomes are not available. Nevertheless, we have shown that after bisoprolol treatment, calculated inotropy was significantly reduced after 2 hours, suggesting that bisoprolol has a direct effect on cardiac power. The transient reduction in SV, CO, and inotropy suggests that bisoprolol has both an inotropic and chronotropic effect. This effect on cardiac muscle function is not synchronous as $\mathrm{SV}, \mathrm{CO}$, and inotropy had returned to baseline values by 6 weeks but the reduction in HR persisted.

Bisoprolol has an acute effect on CO evidenced both in our study and others (40). We also found no difference in CO between $\mathrm{T} 0$ and $\mathrm{TF} 0$, which confirms the findings of others that the non-acute effect in $\mathrm{CO}$ remains unchanged after long-term bisoprolol treatment (41). If the primary effect of bisoprolol is to reduce $\mathrm{CO}$, then it may appear strange that after 6 weeks of treatment, normotension has resulted, yet $\mathrm{CO}$ is unchanged. Thus, bisoprolol, either directly or indirectly, must have a lasting effect on SVR whereas, the effect on $\mathrm{CO}$ is consistently transient. In fact, calculated SVR was significantly reduced $(\mathrm{P}=0.038)$ after 6 weeks of treatment.

It might be expected that $\mathrm{CO}$ would be related to calculated inotropy, and that any effect of bisoprolol would be similar for both. Our study raised interesting findings because although there was no long-lasting effect on CO, there was a more lasting effect reducing calculated inotropy. 


\section{Study limitations}

There are some limitations in our study. Firstly, during prestudy assessment, many patients needed to be excluded, so completing the study took longer than expected, and only a small number of patients could be recruited. Secondly, our study was part of a larger study (an open-label, placebo runin study to investigate the genetic and biomedical predictors of blood pressure response to bisoprolol after 6 weeks treatment), which did not require longitudinal parallel controls. Therefore, we did not have a control group to ensure that diurnal variation, meals, and other factors did not account for changes in haemodynamics. Despite this, our findings were very consistent with many other studies $(40,42)$. Takakuwa also showed that diurnal variations in sBP and dBP in hypertensive patients were small, about \pm 3.5 and $\pm 2.6 \mathrm{mmHg}$, respectively, and that the variation in daytime CO and SV was only $5 \%$ (43). The changes in our study greatly exceeded this, thus we conclude that changes in blood pressure and haemodynamic parameters were most likely due to antihypertensive treatment. Thirdly, this study has not assessed the accuracy and precision of USCOM in the context of hypertension, although several studies have assessed the accuracy of USCOM in a variety of settings. In expert hands the limits of agreement are less than $5 \%$, although under other settings this can vary up to $30 \%$. In our study, we have shown that its trends and readings for parameters such as HR and CO are very similar to those reported by many others.

\section{Future studies}

Future studies evaluating the effects of antihypertensive therapy may utilise USCOM and its calculated parameters when evaluating haemodynamic effects and trends. Patients with different types of hypertension may respond differently to bisoprolol. Thus, haemodynamic derangements should be investigated separately for isolated diastolic hypertension, isolated systolic hypertension, and combined systolic and diastolic hypertension.

\section{Conclusions}

In conclusion, our results demonstrate that low-dose bisoprolol has short-term, acute haemodynamic effects that are as evident at 6 weeks after treatment as they are on day 1 , and the short term inotropic and chronotropic effects are not necessarily synchronous, as a relative bradycardia persists for longer than a reduced SV, CO, and inotropy. Further, the long-term effects of bisoprolol on reducing blood pressure are due more to changes that reset systemic vascular resistance rather than on cardiac effects. USCOM may be a valuable tool for assessing such effects.

\section{Acknowledgments}

We would like to thank Professor Timothy H. Rainer, Dr. Miya Cheng and Dr. Lester Critchley for helping with patient recruitment and the whole study procedures.

Funding: This work was supported by the Research Foundation of Shenzhen Baoan Women's and Children's Hospital, Jinan University (BAFY 2020001).

\section{Footnote}

Reporting Checklist: The authors have completed the STROBE reporting checklist. Available at http://dx.doi. org/10.21037/atm-21-1796

Data Sharing Statement: Available at http://dx.doi. org/10.21037/atm-21-1796

Conflicts of Interest: All authors have completed the ICMJE uniform disclosure form (available at http://dx.doi. org/10.21037/atm-21-1796). The authors have no conflicts of interest to declare.

Ethical Statement: The authors are accountable for all aspects of the work in ensuring that questions related to the accuracy or integrity of any part of the work are appropriately investigated and resolved. The study was approved by the Joint Clinical Research Ethics Committee of the Chinese University of Hong Kong and New Territories East Cluster (CUHK-NTEC) (CREC Ref. No.: 2011.616-T), and informed written consent was obtained from all patients. The study was conducted in accordance with the Declaration of Helsinki (as revised in 2013).

Open Access Statement: This is an Open Access article distributed in accordance with the Creative Commons Attribution-NonCommercial-NoDerivs 4.0 International License (CC BY-NC-ND 4.0), which permits the noncommercial replication and distribution of the article with the strict proviso that no changes or edits are made and the original work is properly cited (including links to both the formal publication through the relevant DOI and the license). 
See: https://creativecommons.org/licenses/by-nc-nd/4.0/.

\section{References}

1. Taler SJ. Initial Treatment of Hypertension. N Engl J Med 2018;378:636-44.

2. Ezzati M, Vander Hoorn S, Lawes CM, et al. Rethinking the "diseases of affluence" paradigm: global patterns of nutritional risks in relation to economic development. PLoS Med 2005;2:e133.

3. Thom T, Haase N, Rosamond W, et al. Heart disease and stroke statistics--2006 update: a report from the American Heart Association Statistics Committee and Stroke Statistics Subcommittee. Circulation 2006;113:e85-151.

4. Virani SS, Alonso A, Benjamin EJ, et al. Heart Disease and Stroke Statistics-2020 Update: A Report From the American Heart Association. Circulation 2020;141:e139-e596.

5. Lu J, Lu Y, Wang X, et al. Prevalence, awareness, treatment, and control of hypertension in China: data from 1.7 million adults in a population-based screening study (China PEACE Million Persons Project). Lancet 2017;390:2549-58.

6. Vasan RS, Larson MG, Leip EP, Kannel WB, Levy D. Assessment of frequency of progression to hypertension in non-hypertensive participants in the Framingham Heart Study: a cohort study. Lancet 2001;358:1682-6.

7. World Health Organization (WHO). New data highlight increases in hypertension, diabetes incidence. 2012. Available online: https://www.who.int/mediacentre/news/ releases/2012/world_health_statistics_20120516/zh/

8. Egan B, Schmouder R. The importance of hemodynamic considerations in essential hypertension. Am Heart J 1988;116:594-9.

9. McEniery CM, Cockcroft JR, Roman MJ, et al. Central blood pressure: current evidence and clinical importance. Eur Heart J 2014;35:1719-25.

10. Martínez-Milla J, Raposeiras-Roubín S, Pascual-Figal DA, et al. Role of Beta-blockers in Cardiovascular Disease in 2019. Rev Esp Cardiol (Engl Ed) 2019;72:844-52.

11. Oparil S, Acelajado MC, Bakris GL, et al. Hypertension. Nat Rev Dis Primers 2018;4:18014.

12. Law M, Wald N, Morris J. Lowering blood pressure to prevent myocardial infarction and stroke: a new preventive strategy. Health Technol Assess 2003;7:1-94.

13. Williams B, Mancia G, Spiering W, et al. 2018 Practice Guidelines for the management of arterial hypertension of the European Society of Hypertension and the European
Society of Cardiology: ESH/ESC Task Force for the Management of Arterial Hypertension. J Hypertens 2018;36:2284-309.

14. Akbar S, Alorainy MS. The current status of beta blockers' use in the management of hypertension. Saudi Med J 2014;35:1307-17.

15. Nieminen T, Lehtimäki T, Laiho J, et al. Effects of polymorphisms in beta1-adrenoceptor and alpha-subunit of $\mathrm{G}$ protein on heart rate and blood pressure during exercise test. The Finnish Cardiovascular Study. J Appl Physiol (1985) 2006;100:507-11.

16. Sõber S, Laan M, Annilo T. MicroRNAs miR-124 and miR-135a are potential regulators of the mineralocorticoid receptor gene (NR3C2) expression. Biochem Biophys Res Commun 2010;391:727-32.

17. McEniery CM, Yasmin, Maki-Petaja KM, et al. The impact of cardiovascular risk factors on aortic stiffness and wave reflections depends on age: the AngloCardiff Collaborative Trial (ACCT III). Hypertension 2010;56:591-7.

18. McEniery CM, Yasmin, Wallace S, et al. Increased stroke volume and aortic stiffness contribute to isolated systolic hypertension in young adults. Hypertension 2005;46:221-6.

19. Deary AJ, Schumann AL, Murfet H, et al. Influence of drugs and gender on the arterial pulse wave and natriuretic peptide secretion in untreated patients with essential hypertension. Clin Sci (Lond) 2002;103:493-9.

20. Aoka Y, Hagiwara N, Kasanuki H. Heterogeneity of hemodynamic parameters in untreated primary hypertension, and individualization of antihypertensive therapy based on noninvasive hemodynamic measurements. Clin Exp Hypertens 2013;35:61-6.

21. Smith RD, Levy P, Ferrario CM. Value of noninvasive hemodynamics to achieve blood pressure control in hypertensive subjects. Hypertension 2006;47:771-7.

22. Chong SW, Peyton PJ. A meta-analysis of the accuracy and precision of the ultrasonic cardiac output monitor (USCOM). Anaesthesia 2012;67:1266-71.

23. Beigel R, Cercek B, Luo H, et al. Noninvasive evaluation of right atrial pressure. J Am Soc Echocardiogr 2013;26:1033-42.

24. Wong LS, Yong BH, Young KK, et al. Comparison of the USCOM ultrasound cardiac output monitor with pulmonary artery catheter thermodilution in patients undergoing liver transplantation. Liver Transpl 2008;14:1038-43.

25. McNamara H, Barclay P, Sharma V. Accuracy and 
precision of the ultrasound cardiac output monitor (USCOM 1A) in pregnancy: comparison with threedimensional transthoracic echocardiography. Br J Anaesth 2014;113:669-76.

26. Nathanson V. Revising the Declaration of Helsinki. BMJ 2013;346: f2837.

27. ICH expert working group. ICH Topic E6 Guideline for Good Clinical Practice. 2016. Available online: https:// www.ema.europa.eu/en/documents/scientific-guideline/ ich-e-6-r2-guideline-good-clinical-practice-step-5_en.pdf

28. World Health Organization (WHO). What is raised blood pressure (hypertension)? 2013. Available online: https:// www.who.int/news-room/q-a-detail/q-as-on-hypertension

29. Horizon Scanning Technology Horizon Scanning report. USCOM: Ultrasound cardiac output monitor for patients requiring haemodynamic monitoring. 2007. Available online: http://www.horizonscanning.gov.au/internet/ horizon/publishing.nsf/Content/58685F8B48CC9EE7C A2575AD0080F340/\$File/HSR\%20-\%20USCOM\%20 Final.pdf

30. Smith BE, Madigan VM. Non-invasive method for rapid bedside estimation of inotropy: theory and preliminary clinical validation. Br J Anaesth 2013;111:580-8.

31. Dhanani S, Barrowman NJ, Ward RE, et al. Intra- and inter-observer reliability using a noninvasive ultrasound cardiac output monitor in healthy anesthetized children. Paediatr Anaesth 2011;21:858-64.

32. Sabidó M, Hohenberger T, Grassi G. Pharmacological intervention in hypertension using beta-blockers: Realworld evidence for long-term effectiveness. Pharmacol Res 2018;130:191-7.

33. Dézsi CA, Szentes V. The Real Role of $\beta$-Blockers in Daily Cardiovascular Therapy. Am J Cardiovasc Drugs 2017;17:361-73.

34. Momčilović S, Jovanović A, Radojković D, et al.

Population pharmacokinetic analysis of bisoprolol in type 2 diabetic patients with hypertension. Eur J Clin Pharmacol 2020;76:1539-46.

35. Uehara Y, Takada S, Hirawa N, et al. Vasoconstrictors and renal protection induced by beta 1-selective adrenoceptor antagonist bisoprolol. J Cardiovasc Pharmacol 1994;23:897-906.

36. Sinagra $\mathrm{G}$, Corrà U, Contini $\mathrm{M}$, et al. Choosing among $\beta$-blockers in heart failure patients according to $\beta$-receptors' location and functions in the cardiopulmonary system. Pharmacol Res 2020;156:104785.

37. Mulder E, Basit S, Oben J, et al. Accuracy and precision of USCOM versus transthoracic echocardiography before and during pregnancy. Pregnancy Hypertens 2019;17:138-43.

38. Man in't Veld AJ, Van den Meiracker AH, Schalekamp MA. Do beta-blockers really increase peripheral vascular resistance? Review of the literature and new observations under basal conditions. Am J Hypertens 1988;1:91-6.

39. Zhou WJ, Wang RY, Li Y, et al. A randomized controlled study on the effects of bisoprolol and atenolol on sympathetic nervous activity and central aortic pressure in patients with essential hypertension. PLoS One 2013;8:e72102.

40. Steinmann E, Pfisterer M, Burkart F. Acute hemodynamic effects of bisoprolol, a new beta 1 selective adrenoreceptor blocking agent, in patients with coronary artery disease. J Cardiovasc Pharmacol 1986;8:1044-50.

41. Parrinello G, Paterna S, Torres D, et al. One-year renal and cardiac effects of bisoprolol versus losartan in recently diagnosed hypertensive patients: a randomized, doubleblind study. Clin Drug Investig 2009;29:591-600.

42. Leeman M, van de Borne P, Collart F, et al. Bisoprolol and atenolol in essential hypertension: effects on systemic and renal hemodynamics and on ambulatory blood pressure. J Cardiovasc Pharmacol 1993;22:785-91.

43. Takakuwa H, Ise T, Kato T, et al. Diurnal variation of hemodynamic indices in non-dipper hypertensive patients. Hypertens Res 2001;24:195-201.
Cite this article as: Zeng $W$, Tomlinson B. Temporal haemodynamic changes after bisoprolol treatment in patients with uncontrolled hypertension. Ann Transl Med 2021;9(11):923. doi: $10.21037 /$ atm-21-1796 